\title{
The healthcare needs of chronic obstructive pulmonary disease patients in the last year of life
}

\author{
Helena Elkington, Patrick White Department of General Practice and Primary Care, King's College London, \\ London, Julia Addington-Hall Department of Palliative Care and Policy, King's College London, London, \\ Roger Higgs Department of General Practice and Primary Care, King's College London, London and \\ Polly Edmonds Department of Palliative Care and Policy, King's College London, London, UK
}

\begin{abstract}
Chronic obstructive pulmonary disease (COPD) causes almost as many deaths as lung cancer, yet evidence about the impact of COPD in the latter stages of illness is limited. We assessed the healthcare needs of COPD patients in the last year of life through a retrospective survey of the informants of 399 deaths from COPD in four London health authorities between January and May 2001. We assessed symptoms, day to day functioning, contact with health and social services, formal and informal help with personal care, information received and place of death.

We obtained data on 209 (52\%) deceased subjects (55\% male), average age at death was 76.8 years. Based on the reports of informants of the deaths: $98 \%$ were breathless all the time or sometimes in the last year of life; other symptoms reported all the time or sometimes included fatigue or weakness $(96 \%)$, low mood $(77 \%)$ and pain $(70 \%)$; breathlessness was partly relieved in over $50 \%$ of those treated; control of other symptoms was poor, with low mood relieved in $8 \%$ and no treatment for low mood received by $82 \%$ of sufferers; $41 \%$ left the house less than once a month or never; $47 \%$ were admitted to hospital at least twice in the last year of life; $51 \%$ received regular check-ups for their chest; $36 \%$ had check-ups by a hospital consultant; 35\% saw their general practitioner (GP) less than once every three months or never; $63 \%$ knew they might die; $67 \%$ died in hospital. Patients who died from COPD lacked surveillance and received inadequate services from primary and secondary care in the year before they died. The absence of palliative care services highlights the need for research into appropriate models of care to address uncontrolled symptoms, information provision and end of life planning in COPD. Palliative Medicine 2005; 19: 485-491
\end{abstract}

Key words: chronic obstructive pulmonary disease; end of life; needs assessment; palliative care; symptoms

\section{Introduction}

Chronic obstructive pulmonary disease (COPD) is a progressive disease, which accounted for 25673 deaths in England and Wales in 2003, 5.4\% of all male and 4.2\% of all female deaths. ${ }^{1}$ By comparison, lung cancer (which has a much shorter time course) caused 28749 deaths in the same year. COPD is the largest single cause of emergency admissions to hospital in London where this study was conducted. ${ }^{2}$ Mortality in severe COPD is between 36 and $50 \%$ at two years after admission for an acute exacerbation. ${ }^{3,4}$ Research evidence about the impact of COPD on symptoms, activities of daily living,

\footnotetext{
Address for correspondence: Dr Patrick White, Senior Lecturer, Department of General Practice and Primary Care, Guy's King's and St Thomas' School of Medicine, King's College London, 5 Lambeth Walk, London SE11 6SP, UK.

E-mail: patrick.white@kcl.ac.uk
}

and use of services in the latter stages of illness is limited. ${ }^{5,6}$ Studies have often involved small numbers of patients or have only selected subjects from an outpatient setting. ${ }^{5,6}$ An exception is the Study to Understand Prognoses and Preferences for Outcomes and Risks of Treatment (SUPPORT study) which reported on the last year of life of patients recruited whilst hospitalized with COPD between 1989 and 1994 in the USA. ${ }^{4}$ However, patients known to services are unlikely to be representative of all patients with COPD at the end of life. Edmonds et al. reported on 87 deceased chronic lung disease patients from the 1990 population-based Regional Study of Care for the Dying in the UK ( 82 had COPD). ${ }^{7}$ As in the SUPPORT study, the severe impact of the disease and the considerable health care needs of these patients were evident. Both studies are now dated, and the study reported here was therefore designed to provide a comprehensive, up to date account of the health and social service needs of a population-based 
sample of COPD patients in the last year of life and their contact with health services.

\section{Method}

We carried out a questionnaire survey of the informants of COPD deaths (the people who register the death) between October and November 2001. Informants of COPD deaths in four health authorities covering inner city and suburban settings were identified and mailed the questionnaire by the Office for National Statistics (ONS). ONS has a database of all registered deaths, which includes the underlying cause of death and the name of the informant. ONS conducted the mailing to ensure the confidentiality of the informants' identities. Their details were not passed on to the research team. The informants' accounts were used as a proxy for the deceased person's experience. ${ }^{8}$ It was assumed that the informant would be close to the deceased and involved in caring for them in the last months of life. If this was not the case, the informant was asked to forward the questionnaire to whomever they felt was the most appropriate person.

We modelled the questionnaire on a postal questionnaire to the informants of deaths in a previous palliative care survey. ${ }^{9}$ The questionnaire (Views Of Informal Carers - Evaluation of Services, VOICES) was a cost effective and practical alternative to interviews of carers of the dying in retrospective post-bereavement surveys. In this study, a COPD-specific version of the VOICES questionnaire was developed. Ethical approval was obtained from each of the research ethics committees in the four areas in which deaths were identified.

\section{Subjects}

ONS identified 399 COPD deaths across the four health authorities between January and May 2001 (inclusive), using the ICD ten codes J43.1-J44.9. J43 represents emphysema and J44 other COPD. J40 (bronchitis not specified as acute or chronic), J41 (simple and mucopurulent chronic bronchitis) and J42 (unspecified chronic bronchitis) were excluded to ensure the underlying cause of death was COPD. In 2001, J40-42 accounted for 1.9\% of all the deaths in categories $\mathrm{J} 40-44 .^{10}$ Informants of deaths were sent the VOICES questionnaire, together with an information sheet and a reply slip to complete and return to ONS if they wanted no further part in the study. Reminder mailings were sent three and six weeks later. Completed questionnaires were returned to ONS and subsequently forwarded to the investigators. The mailing was performed between five and ten months after the death of the deceased.

\section{The questionnaire}

We developed the COPD-specific questionnaire using indepth interviews with 28 informants of COPD deaths. ${ }^{11}$ This was followed by a pilot questionnaire survey of a further 60 informants of COPD deaths, with follow-up telephone interviews to five respondents who agreed to be contacted when they returned the questionnaire. The pilot mailing contributed to questionnaire design and presentation as well as serving to test the administrative elements of the main survey by ONS. The follow-up telephone interviews provided an insight into the informant's understanding and interpretation of specific questions.

There were seven sections in the new COPD specific VOICES questionnaire (Figure 1). It retained the style and broad content of the original VOICES questionnaire. Additional questions applicable to COPD focused on respiratory nurse specialists and community nurses, COPD-related symptoms, home oxygen, role of the general practitioner (GP), and check-ups for chest trouble. Relief of symptoms (breathlessness, cough, weakness, fatigue, appetite, sleep, low mood, anxiety and panic) with treatment was reported with the terms 'a lot', 'some', 'a little', 'don't know' except in the case of pain where it was reported as 'completely relieved all the time', 'completely relieved some of the time', 'partly relieved', 'not relieved at all', 'don't know'. Three questions on experience in hospital in section $\mathrm{C}$ were modelled on questions from the UK in-patient survey and one question on GP care was derived from the 1998 General Practice Survey. ${ }^{12,13}$ The question on the ethnic group of the deceased was modelled on that in the 2001 Census. ${ }^{14}$ Male and female versions of the questionnaire were produced. The final versions of the questionnaire were approved by the project multidisciplinary steering group.

\section{Analysis}

The data were analysed using the statistical package for the social sciences (SPSS Inc, Chicago, USA). Associations were sought using $t$-tests, Chi square, and univariate and multivariate logistic regression.

\begin{tabular}{|l|l|}
\hline Section A & Help at home from health and social services \\
\hline Section B & Symptoms and treatment including home oxygen, and any other illnesses \\
\hline Section C & Experience of services from the GP and hospital \\
\hline Section D & Admission to a nursing, residential or old people's home \\
\hline Section E & Check up appointments (hospital, GP or at home) \\
\hline Section F & Information received about the illness \\
\hline Section G & Circumstances surrounding the death \\
\hline
\end{tabular}

Figure 1 Topic sections of the COPD-specific questionnaire. 


\section{Results}

\section{Demographic data}

Two hundred and nine (52\%) completed questionnaires were returned. Of the deceased about whom responses were received, $55.5 \%$ were male $(53.2 \%$ among nonrespondents) and the average age at death was 76.8 years (range: 37-98 years) (77.2 years among non-respondents). A total of 197 of the deceased about whom questionnaires were returned were white, one was Asian and one was Black Caribbean (ten missing responses). There were no significant differences in age or sex between the deceased about whom responses were received and those about whom responses were not received. Most respondents $(81 \%)$ were the spouse or partner of the deceased or their son or daughter.

\section{Symptoms and treatment received by the deceased}

Table 1 shows the symptoms experienced and the treatment received by the deceased in the last year of life, and the extent to which treatment relieved symptoms. Almost all the deceased were reported to have been breathless and to have had weakness or fatigue all the time or sometimes in the last year of life. Insomnia, low mood, anxiety or panic attacks, and pain were prominent symptoms reported to have been experienced by most patients. The majority of patients who were breathless either all the time or sometimes, were reported to have received treatment for their symptoms, as were two-thirds of those reported to have had pain, while only a minority of those with psychological symptoms were reported to have received treatment. Among those receiving home oxygen, over half the respondents $(53 \%)$ reported that the deceased needed oxygen to go out.

\section{Contact with health services}

Reported health service use in the last year of life is summarized in Table 2. Some $39 \%$ of informants felt that deceased subjects who had been admitted to hospital had been discharged too soon. Half of the deceased (104) were reported to have received regular check-ups for their chest problem in the last year of life, $34(16 \%)$ with both the GP and specialist. A total of $13 \%$ had contact with a nurse for their chest trouble.

\section{Informal care and social services; frequency of leaving the house; and place of death}

Other aspects of the deceased and their personal care (relationship of respondent to deceased, frequency of leaving the house, place of death and help received at home with personal care) are shown in Table 3. Most subjects received help from family and friends (95\%), whether with household tasks $(84 \%)$, personal care $(60 \%)$ or medicines $(55 \%)$. Less than a half received help with
Table 1 Symptoms and treatment received in the last year of life

\begin{tabular}{|c|c|}
\hline & $n(\%)$ \\
\hline \multicolumn{2}{|l|}{ Symptoms all the time/sometimes } \\
\hline Breathlessness & $200(98)$ \\
\hline Cough & $163(80)$ \\
\hline Weakness/fatigue & $195(96)$ \\
\hline Appetite & $166(81)$ \\
\hline Hard to sleep at night & $160(77)$ \\
\hline Low mood & $158(77)$ \\
\hline Anxiety/panic attacks & $109(53)$ \\
\hline Pain & $147(72)$ \\
\hline \multicolumn{2}{|c|}{ Treatment received for symptoms present all the time/sometime } \\
\hline Breathlessness & $166(85)$ \\
\hline Hard to sleep at night & $30(19)$ \\
\hline Low mood & $29(18)$ \\
\hline Anxiety/panic attacks & $18(17)$ \\
\hline Pain & $97(66)$ \\
\hline \multicolumn{2}{|l|}{ Symptoms relieved by treatment 'a lot' or 'some'a } \\
\hline Breathlessness & $94(57)$ \\
\hline Difficulty sleeping & $18(58)$ \\
\hline Low mood & $12(41)$ \\
\hline Anxiety/panic attacks & $10(56)$ \\
\hline Pain $^{a}$ & $21(21)$ \\
\hline \multicolumn{2}{|l|}{ Oxygen received } \\
\hline Yes $^{b}$ & $83(40)$ \\
\hline Concentrator & $21(10)$ \\
\hline Cylinder & $41(20)$ \\
\hline Concentrator and cylinder & $20(10)$ \\
\hline No & $122(60)$ \\
\hline \multicolumn{2}{|l|}{ Use of oxygen ${ }^{c}$} \\
\hline$<15 / 24$ hours & $42(51)$ \\
\hline$\geq 15 / 24$ hours & 32 (39) \\
\hline \multicolumn{2}{|l|}{ Times oxygen was needed } \\
\hline At all times & $32(40)$ \\
\hline With physical activity (dressing/climbing stairs) & $41(51)$ \\
\hline At times of anxiety & $28(35)$ \\
\hline With a chest infection & $39(49)$ \\
\hline
\end{tabular}

aSymptom relief with treatment, was reported as 'a lot' or 'some' with the exception of pain which was reported as 'completely relieved all the time' or 'completely relieved some of the time'.

${ }^{b}$ One missing among those that responded yes.

${ }^{\mathrm{C}}$ Don't know responses have not been included.

night care. Little help was received from health or social services with these tasks, with $70 \%$ receiving none.

Significantly more informants (88 versus $66 \% ; \chi^{2}=$ 9.68, $\mathrm{P}=0.008$ ) of subjects who died at home rather than in hospital felt that they died in the right place.

\section{Information at the end of life}

Some $56 \%$ of informants were aware that the deceased might die, 40\% were not aware and 4\% did not know. Among those who did not know that the deceased might die, $78 \%$ would definitely or probably liked to have known. Of the deceased, $63 \%$ were reported to know definitely or probably that he or she might die. 
Table 2 Reported health service use in the last year of life

\begin{tabular}{|c|c|}
\hline & $n(\%)$ \\
\hline \multicolumn{2}{|l|}{ Contact with GP } \\
\hline At least once a week & $7(4)$ \\
\hline At least once a month but not every week & $57(30)$ \\
\hline Once every two or three months & $59(31)$ \\
\hline Less than every three months & $54(29)$ \\
\hline Never & $12(6)$ \\
\hline \multicolumn{2}{|l|}{ Contact with district nurse $e^{a}$} \\
\hline Any contact & $20(10)$ \\
\hline Never & $181(88)$ \\
\hline \multicolumn{2}{|l|}{ Contact with respiratory nurse specialist ${ }^{a}$} \\
\hline Any contact & $12(5)$ \\
\hline Never & $186(92)$ \\
\hline \multicolumn{2}{|l|}{ Admission to hospital } \\
\hline Never & $47(23)$ \\
\hline Once & $58(29)$ \\
\hline Twice & $31(15)$ \\
\hline Three or more times & $65(32)$ \\
\hline \multicolumn{2}{|l|}{ Outpatient check-ups for chest problem } \\
\hline Yes & $104(51)$ \\
\hline No & $87(42)$ \\
\hline Don't know & $14(7)$ \\
\hline \multicolumn{2}{|l|}{ Who provided check-ups ${ }^{b}$} \\
\hline GP & $55(26)$ \\
\hline Hospital consultant & $76(36)$ \\
\hline Specialist chest nurse & $15(7)$ \\
\hline Practice nurse & $8(4)$ \\
\hline District nurse & $4(2)$ \\
\hline \multicolumn{2}{|l|}{ Services provided by GP } \\
\hline Emergency care & $58(29)$ \\
\hline Repeat prescriptions & $187(95)$ \\
\hline Changing medication & $88(45)$ \\
\hline Emotional support & $21(11)$ \\
\hline Arranging extra help at home & $18(9)$ \\
\hline $\begin{array}{l}\text { Providing information about the deceased's lung } \\
\text { condition }\end{array}$ & $29(15)$ \\
\hline Regular check-ups for lung condition & 37 (19) \\
\hline Referral to outpatients & $82(42)$ \\
\hline
\end{tabular}

aDon't know responses have not been included.

${ }^{b}$ Respondents could tick as many boxes as applied. A total of $104(50 \%)$ had check-ups.

\section{Associations between symptoms and other patient variables and contact with the GP and hospital}

Regular chest check-ups, frequent cough, leaving the house at least once a month but not every week, and having a GP perceived to be willing to visit the deceased at home, were all independently associated with contact with the GP at least once every three months (multivariate logistic regression) (Table 4a). Pain all the time, leaving the house once a week or more, and use of home oxygen were all independently associated with seeing the hospital consultant for chest check-ups (multivariate logistic regression) (Table 4b). Cough all the time or sometimes was associated with not seeing the hospital consultant for check-ups. Other patient characteristics including demographic variables, symptom variables and
Table 3 Relationship of respondent to deceased, frequency of leaving the house, place of death and help received at home with personal care

\begin{tabular}{|c|c|}
\hline & $n(\%)$ \\
\hline \multicolumn{2}{|l|}{ Relationship of respondent to deceased } \\
\hline Spouse/partner & 60 (29) \\
\hline Son/daughter & $107(52)$ \\
\hline Brother/sister & 17 (8) \\
\hline Son-in-law/daughter-in-law & $5(2)$ \\
\hline Brother-in-law/sister-in-law & $2(1)$ \\
\hline Parent & $3(2)$ \\
\hline Other relative & $12(6)$ \\
\hline \multicolumn{2}{|l|}{ Place of death } \\
\hline Hospital & $137(67)$ \\
\hline Home & $50(25)$ \\
\hline Residential/nursing home & $13(6)$ \\
\hline Hospice & $1(1)$ \\
\hline In transit to hospital & $2(1)$ \\
\hline \multicolumn{2}{|l|}{ Frequency of leaving house } \\
\hline Every day & $22(11)$ \\
\hline At least once a week but not every day & $64(31)$ \\
\hline At least once a month but not every week & $35(17)$ \\
\hline Less than once a month & 39 (19) \\
\hline Never & $44(21)$ \\
\hline \multicolumn{2}{|l|}{ Help from family and friends ${ }^{a}$} \\
\hline Personal care & $112(60)$ \\
\hline Household tasks & $160(84)$ \\
\hline Night-time care & $87(48)$ \\
\hline Taking of medicines & $102(55)$ \\
\hline None & $25(13)$ \\
\hline \multicolumn{2}{|c|}{ Time family and friends spent on these tasks (hours/week) } \\
\hline$<5$ & $24(15)$ \\
\hline $5-10$ & 27 (16) \\
\hline $11-19$ & $29(18)$ \\
\hline $20-39$ & $17(10)$ \\
\hline 40 or more & $68(41)$ \\
\hline \multicolumn{2}{|l|}{ Help from health and social services ${ }^{a}$} \\
\hline Personal care & $46(21)$ \\
\hline Household tasks & $38(18)$ \\
\hline Night-time care & $13(6)$ \\
\hline Taking of medicines & $17(8)$ \\
\hline None & $127(67)$ \\
\hline \multicolumn{2}{|l|}{ Frequency of help from health and social services ${ }^{b}$} \\
\hline At least once a day & $40(64)$ \\
\hline At least once a week, but not every day & $21(33)$ \\
\hline At least once a month, but not every week & $2(3)$ \\
\hline
\end{tabular}

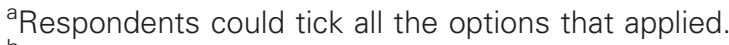
${ }^{\mathrm{b}}$ Any type of help.

services variables were not significantly associated with symptom severity or frequency of contact with services.

\section{Discussion}

Patients who died from COPD had a heavy symptom load in the last year of life, both physical and psychological. They had symptoms typical of COPD such as breathlessness, and also less typical symptoms such as 
Table 4 Characteristics of COPD patients in the last year of life associated with: (a) contact with the GP at least once every three months; (b) seeing the hospital consultant for check-ups of the chest (multiple logistic regression, adjusted odds ratios)

(a) Contact with the GP at least once every three months ${ }^{a}$

\begin{tabular}{|c|c|c|c|c|c|}
\hline & $\begin{array}{l}\text { Adjusted odds } \\
\text { ratio }\end{array}$ & $\begin{array}{l}\text { 95\% Confidence } \\
\text { Interval }\end{array}$ & & $\begin{array}{l}\text { Adjusted odds } \\
\text { ratio }\end{array}$ & $\begin{array}{l}95 \% \text { Confidence } \\
\text { Interval }\end{array}$ \\
\hline How often leave the house & & & How often leave the house & & \\
\hline Every day & 3.03 & $0.25-36.58$ & Every day & 9.33 & $1.62-53.62$ \\
\hline $\begin{array}{l}\text { At least once a week but not } \\
\text { every day }\end{array}$ & 2.72 & $0.73-10.20$ & $\begin{array}{l}\text { At least once a week but } \\
\text { not every day }\end{array}$ & 4.67 & $1.25-17.45$ \\
\hline $\begin{array}{l}\text { At least once a month but not } \\
\text { every week }\end{array}$ & 14.55 & $2.17-97.79$ & $\begin{array}{l}\text { At least once a month but } \\
\text { not every week }\end{array}$ & 3.92 & $0.96-15.99$ \\
\hline Less than once a month & 0.65 & $0.15-2.92$ & Less than once a month & 3.10 & $0.79-12.19$ \\
\hline $\begin{array}{l}\text { Never } \\
\text { GP willing to visit at home }\end{array}$ & 1 & & $\begin{array}{l}\text { Never } \\
\text { Oxygen at home }\end{array}$ & 1 & \\
\hline Always & 23.28 & $1.31-412.42$ & Yes & 5.57 & $2.30-13.45$ \\
\hline Sometimes & 21.78 & $1.29-368.13$ & & & \\
\hline Rarely & 17.63 & $1.07-290.02$ & & & \\
\hline Never & 1 & & Never & 1 & \\
\hline Regular check-ups for chest problem & & & Pain & & \\
\hline Yes & 7.44 & $2.18-25.43$ & $\begin{array}{l}\text { All the time } \\
\text { Sometimes }\end{array}$ & $\begin{array}{r}\mathbf{1 0 . 1 3} \\
1.94\end{array}$ & $\begin{array}{l}2.59-39.70 \\
0.63-6.01\end{array}$ \\
\hline No & 1 & & Rarely or not at all & 1 & \\
\hline Cough & & & Cough & & \\
\hline All the time & 7.74 & $1.45-41.16$ & All the time & 0.25 & $0.07-0.92$ \\
\hline Sometimes & 7.07 & $1.58-31.52$ & Sometimes & 0.30 & $0.09-0.98$ \\
\hline Rarely or not at all & 1 & & Rarely or not at all & 1 & \\
\hline
\end{tabular}

a Variables significant in univariate analysis and included in the multiple logistic regression but which did not contribute significantly to the model and not shown here were: 'use of special equipment'; 'how well GP knew deceased'; 'time GP had to listen and discuss'; 'overall perception of GP'.

bariables significant in univariate analysis and included in the multiple logistic regression but which did not contribute significantly to the model and not shown here were: 'age'; 'how subject saw the GP'; 'number of admissions in previous 12 months'.

pain and low mood. Rates of contact with health professionals were low, and housebound patients were less likely to have had contact despite the greater severity of disease implied by their immobility. A minority of patients received help from health and social services with personal care, household tasks, night-time care and administration of medicines.

\section{A retrospective post-bereavement study}

We adopted a retrospective post-bereavement approach to data collection. ${ }^{15,16}$ Informants were used as proxies for the deceased's experience, as well as providing their own perspective on events leading to the death. Retrospective data collection was used because of the difficulties in conducting a prospective study with dying patients and in identifying COPD patients who were at high risk of dying. ${ }^{4}$ This method makes possible the inclusion of a complete sample of people who die, not just those known to services. The limited health and social care received by most patients highlights the importance of this population-based approach when seeking to understand need at the end of life.

There are limitations with the retrospective approach. The view of the sufferer could not be included, and the informant's account was made after an interval of five months or more. Agreement between the patient's and the proxy's account is good for aspects of care relating to service provision and communication. ${ }^{8}$ Agreement is better for certain symptoms such as breathlessness and mobility (observable symptoms) than for others such as pain or depression (subjective experience). The shorter the time interval between an event and its report the better the recall. With end of life research it may not be acceptable or appropriate to approach subjects for a proxy account sooner than five months after death. A balance needs to be struck between accuracy of information and avoidance of emotional distress.

The response rate $(52 \%)$, typical of retrospective postbereavement studies in the inner city, means our findings may not completely represent the needs of COPD sufferers at the end of life. Nonetheless, the nonresponders did not differ from the responders in age or sex and the scale of this study is far greater than any previously published study of advanced COPD. There is an under-representation of people from non-white ethnic groups that may be partly explained by the lower numbers of people from ethnic minorities in older age 
groups in the UK. The distribution of preferred place of care in advanced COPD is not known, but where death occurred at home in this study it was more likely to have been seen to be the right place.

\section{Symptoms at the end of life}

Symptoms were similar to those reported previously in qualitative or smaller scale studies. ${ }^{6,7}$ They were not just those associated with COPD such as breathlessness, but also included psychological symptoms such as low mood and symptoms more typically associated with cancer such as pain. Relief of the latter was poor with most of the deceased not even receiving treatment. Informants' reports that in $57 \%$ of the deceased breathlessness had been relieved by treatment 'a lot' or 'some' may partly reflect a comparison with worse breathlessness observed during an exacerbation and subsequently relieved, and in addition may represent some element of response shift in the informant after prolonged observation of the symptom. ${ }^{17}$

\section{Contact with health services}

The GP. A total of $34 \%$ of subjects had contact with their GP at least once every three months in the last year of life. This compares with the study of Edmonds et al., ${ }^{7}$ in which nearly $50 \%$ of subjects saw their GP ten or more times in the last year of life, and the study of Skilbeck et al., ${ }^{5}$ in which $84 \%$ of subjects saw their GP in the previous three months. Our large sample size and the decline in GP home visiting in the last 15 years may explain some of the differences. ${ }^{18}$

Frequency of GP contact was not associated with COPD severity as represented by breathlessness frequency, although it was associated with cough frequency in the multivariate analysis. The low rate of GP contact of both the least and the most mobile subjects (reported as frequency of leaving the house) may reflect the lower healthcare needs of the most mobile (and hence least affected) and the relative inaccessibility of the GP to the least mobile and most severely affected. Those with most frequent GP contact were restricted in their mobility (leaving the house at least once a month, but not every week) but perhaps mobile enough to see the GP when they needed.

Nurses. Only $13 \%$ of subjects saw a nurse at home compared to rates of $40 \%$ (patients with chronic lung disease who saw a district nurse in the last year of life), and $34 \%$ (patients with advanced COPD who saw the district nurse) in earlier studies, although in those studies the visit may have been for a co-existent problem and not the chest. ${ }^{5,6}$ Contact with COPD patients by respiratory nurse specialists may be on the increase in the National Health Service (NHS) since this survey was carried out, but the marked contrast with the regular nurse contact seen in lung cancer is likely to have remained. ${ }^{6}$

Hospital. Hospital admission of more than half the subjects twice or more in the last year of life confirms the severity of COPD. Only one-third received their checkups in hospital and they were much more likely to be the most mobile, to have had pain all the time and to have had home oxygen. Housebound patients not on oxygen were likely to remain untended by a specialist until a crisis intervened. Since patients who were housebound because of COPD were also less likely to be seen by a GP, there appears to be a need for planned intervention in housebound patients with severe COPD.

Home oxygen. Intermittent use of oxygen has a limited role in advanced COPD so the finding that only half of those patients who received home oxygen were reported to have used it for 15 or more hours per day confirms the view that the use of oxygen in severe COPD is inadequate whether because of under-prescription or under-use. ${ }^{19}$

Palliative care. The need for palliative care (control of symptoms, and management of psychological, social and spiritual problems) in many of the subjects in this study seems clear. ${ }^{20}$ Almost half of the informants in our study had not been aware that the deceased might die, yet subjects were housebound with a high symptom burden and most were admitted at least twice in the year before death. These observations highlight the difficulties in advanced COPD in making a prognosis, in identifying the terminal phase of the illness, and in introducing discussions about the end of life.

\section{Conclusion and implications}

Patients with advanced COPD receive inadequate healthcare and may need regular surveillance to maintain a suitable level of service and to ensure appropriate treatment. Two recent innovations in COPD care, the case management approach of Poole et al. and the incentive payments for COPD management in the new NHS contract for GPs propose schemes which may address this problem. ${ }^{21,22}$ The informal carers of people with advanced COPD who provide most of their care are likely to have considerable support needs which are hardly acknowledged or addressed at present. The absence of involvement of palliative care services highlights the need for new models of care for advanced COPD which take into account the uncertainties surrounding prognosis and address unmet needs in symptom control, information provision and end of life planning.

To view the full questionnaire, please refer to the following website: http://www.palliativemedjournal.com 


\section{Acknowledgements}

We thank ONS for their help in running the questionnaire survey. We thank the informants of the deaths for their generosity in completing questionnaires that in many cases may have caused distress. Finally, we thank Paul Seed for statistical advice, and Cathy Pettinari for advice at the design stage and in developing the questionnaire. This study was funded by the NHS Directorate of Health and Social Care, London, (Research and Development, Responsive Funding Programme) and the Guy's and St Thomas' Charitable Foundation, London. Ethical approval was obtained from the Kings College Hospital NHS Trust Research Ethics Committee.

\section{References}

1 National Statistics. Deaths by age, sex and underlying cause. 2003 registrations: health statistics quarterly 22, Report No.: HSQ22DT2. London: Office for National Statistics, 2004.

2 Damiani M, Dixon J. Managing the pressure. Emergency hospital admissions in London, 1997-2001. London: King's Fund Publishing, 2001.

3 Almagro P, Calbo E, Ochoa de EA, et al. Mortality after hospitalization for COPD. Chest 2002; 121: 1441-48.

4 Connors AFJ, Dawson NV, Thomas C, et al. Outcomes following acute exacerbation of severe chronic obstructive lung disease. The SUPPORT investigators (Study to Understand Prognoses and Preferences for Outcomes and Risks of Treatments). Am J Respir Crit Care Med 1996; 154: 959-67.

5 Skilbeck J, Mott L, Page H, Smith D, HjelmelandAhmedzai S, Clark D. Palliative care in chronic obstructive airways disease: a needs assessment. Palliat Med 1998; 12: 245-54.

6 Gore JM, Brophy CJ, Greenstone MA. How well do we care for patients with end stage chronic obstructive pulmonary disease (COPD)? A comparison of palliative care and quality of life in COPD and lung cancer. Thorax 2000; 55: 1000-1006.

7 Edmonds P, Karlsen S, Khan S, Addington-Hall J. A comparison of the palliative care needs of patients dying from chronic respiratory diseases and lung cancer. Palliat Med 2001; 15: 287-95.

8 McPherson CJ, Addington-Hall JM. Judging the quality of care at the end of life: can proxies provide reliable information? Soc Sci Med 2003; 56: 95-109.
9 Addington-Hall J, Walker L, Jones C, Karlsen S, McCarthy M. A randomised controlled trial of postal versus interviewer administration of a questionnaire measuring satisfaction with, and use of, services received in the year before death. $J$ Epidemiol Community Health 1998; 52: 802-807.

10 National Statistics. Mortality statistics cause: review of the Registrar General on deaths by cause, sex and age, in England and Wales in 2001, Report No.: 28. Norwich: HMSO, 2004.

11 Elkington H, White PT, Addington-Hall J, Higgs R, Pettinari CJ. The last year of life of COPD: a qualitative study of symptoms and services. Respir Med 2004; 98: 439-45.

12 Airey C, Bruster S, Calderwood L, Erens B, Pitson L, Richards N. National survey of NHS patients - coronary heart disease 1999. National report: summary of findings. London: Department of Health, 2001.

13 Airey C, Bruster S, Erens B, Lilley S, Pickering K, Pitson L. National survey of NHS patients: general practice 1999. London: NHS Executive, 1999.

14 Smith A. The new ethnicity classification in the Labour Force Survey. Labour Mark Trends 2002; 110: 657-66.

15 Addington-Hall J, McCarthy M. Regional study of care for the dying: methods and sample characteristics. Palliat Med 1995; 9: 27-35.

16 Cartwright $\mathrm{A}$, Seale C. The natural history of the survey: an account of the methodological issues encountered in a study of life before death. London: King's Fund, 1990.

17 Schwartz CE, Rapkin BD. Reconsidering the psychometrics of quality of life assessment in light of response shift and appraisal. Health Qual Life Outcomes 2004; 2: 16.

18 Aylin P, Majeed FA, Cook DG. Home visiting by general practitioners in England and Wales. BMJ 1996; 313: 207-10.

19 Royal College of Physicians. Domiciliary oxygen therapy services. Clinical guidelines and advice for prescribers. London: Royal College of Physicians, 1999.

20 World Health Organization. Palliative care. Geneva: World Health Organization, 2004.

21 Poole PJ, Chase B, Frankel A, Black PN. Case management may reduce length of hospital stay in patients with recurrent admissions for chronic obstructive pulmonary disease. Respirology 2001; 6: 37-42.

22 General Practitioners Committee, the NHS Confederation. New GMS contract 2003. Investing in general practice. London: British Medical Association, 2003. 